\title{
MAXIMUM HEAT TRANSFER RATE DENSITY IN TWO-DIMENSIONAL MINICHANNELS AND MICROCHANNELS
}

\author{
M. Favre-Marinet ${ }^{\mathrm{a}}$,Michel.Favre-Marinet@hmg.inpg.fr \\ S. Le Person ${ }^{\text {a }}$, Stephane.Leperson@hmg.inpg.fr
}

A. Bejan ${ }^{\text {b abejan@duke.edu }}$

a) Laboratoire des Ecoulements Géophysiques et Industriels

CNRS-UJF-INPG, 1025 rue de la Piscine, BP 53 X, 38041, Grenoble Cedex, France

b) Duke University, Department of Mechanical Engineering and Materials Science, Durham, NC 27708-0300, USA

\begin{abstract}
Experimental investigations of the flow and the associated heat transfer were conducted in two-dimensional microchannels in order to test possible size effects on the laws of hydrodynamics and heat transfer and to infer optimal conditions of use from the measurements. The test section was designed to modify easily the channel height e between $1 \mathrm{~mm}$ and $0.1 \mathrm{~mm}$. Measurements of the overall friction factor and local Nusselt numbers show that the classical laws of hydrodynamics and heat transfer are verified for e $>0.4$ $\mathrm{mm}$. For lower values of e, a significant decrease of the Nusselt number is observed, whereas the Poiseuille number continues to have the conventional value of laminar developed flow. The transition to turbulence is not affected by the channel size. For fixed pressure drop across the channel, a maximum of heat transfer rate density is found for a particular value of e. The corresponding dimensionless optimal spacing and heat transfer rate density are in very good agreement with the predictions of Bejan and Sciubba (1992). This paper is the first time that the optimal spacing between parallel plates is determined experimentally.
\end{abstract}

\section{Nomenclature}

b channel width (spanwise direction),

$\mathrm{D}_{\mathrm{h}}$ hydraulic diameter,

e channel height,

$f$ Fanning friction factor,

$\mathrm{h}$ heat transfer coefficient,

$\mathrm{k}$ thermal conductivity,

L channel length,

dimensionless

$\mathrm{W} \cdot \mathrm{m}^{-2} \cdot \mathrm{K}^{-1}$

$\mathrm{W} \cdot \mathrm{m}^{-1} \cdot \mathrm{K}^{-1}$

$\mathrm{m}$ $\mathrm{m}$
$\mathrm{L}^{+}=\frac{\mathrm{L}}{\mathrm{D}_{\mathrm{h}}} \frac{1}{\mathrm{Re}}$,

dimensionless channel length

$l_{h}$ heating resistance length,

$\mathrm{Nu}$ Nusselt number,

$\mathrm{P}$ electric power,

$\mathrm{p}$ pressure,

Po Poiseuille number,

Pr Prandtl number,

$q^{\prime \prime}$ heat flux,

$\tilde{\mathrm{q}}^{\prime \prime}$ dimensionless heat flux,

Q total heat transfer rate,

$\mathrm{Q}_{\mathrm{v}}$ volumetric flowrate,

$\operatorname{Re}=\frac{\rho \mathrm{VD}_{\mathrm{h}}}{\mu} \quad$ Reynolds number

$\mathrm{T}$ temperature,

V channel bulk velocity,

$\mathrm{x}$ abscissa along the channel,

$\mathrm{x}^{+}=\frac{\mathrm{x}}{\mathrm{D}_{\mathrm{h}}} \frac{1}{\mathrm{Re}}$

hydrodynamic entrance parameter, dimensionless

$\mathrm{x}^{*}=\frac{\mathrm{x}}{\mathrm{D}_{\mathrm{h}}} \frac{1}{\operatorname{RePr}}$

thermal entrance parameter,

dimensionless

Greek symbols

$\alpha$ thermal diffusivity,

$\mu$ dynamic viscosity,

$\Pi_{\mathrm{L}}$ pressure drop number,

$\rho$ density,

$\mathrm{m}$

dimensionless

W

N. $\mathrm{m}^{-2}$

dimensionless dimensionless W. $\mathrm{m}^{-2}$

W

$\mathrm{m}^{3} / \mathrm{s}$

dimensionless

${ }^{\circ} \mathrm{C}$

$\mathrm{m} \cdot \mathrm{s}^{-1}$

$\mathrm{m}$ $\mathrm{m}^{2} \cdot \mathrm{s}^{-1}$

$\mathrm{kg} \cdot \mathrm{m}^{-1} \cdot \mathrm{s}^{-1}$

dimensionless

$\mathrm{m}^{3} \cdot \mathrm{s}^{-1}$ 
$\tau \quad$ wall shear stress,

$\mathrm{N} \mathrm{m}^{-2}$

Subscripts

$\begin{array}{ll}\text { ( ) av } & \text { average } \\ ()_{c} & \text { critical } \\ ()_{f} & \text { fluid } \\ ()_{\text {film }} & \text { film } \\ ()_{\text {in }} & \text { inlet } \\ ()_{\text {out }} & \text { outlet } \\ ()_{w} & \text { wall }\end{array}$

\section{INTRODUCTION}

The development of microscale systems has grown rapidly during last decades, making possible many applications. In the field of heat transfer, use of microchannels seems very promising for cooling electronic equipment. Enhancement of heat transfer coefficient is obviously expected with reduction of length scales, and this has been observed many times starting with the experiments of Tuckerman and Pease (1982). However, at the same time, pressure losses are rising very rapidly when the passage of the flow is strongly reduced. It is therefore important to consider the optimization of the design of microchannels for proper application to heat transfer problems.

Scaling laws pertaining to the hydrodynamics and heat transfer in microchannels are not clearly established, although many studies have been devoted to this subject in recent years. Published experimental results question the applicability of classical laws (friction factor, laminarturbulent transition, heat exchange coefficient) when the characteristic dimensions of the channel are of the order of several hundred to one $\mu \mathrm{m}$. Recent publications show contradictory conclusions regarding hydrodynamics [see, for example, Flockhart and Dhariwal (1998), Pfund et al. (2000), Qu et al. (2002a)]. Moreover, results on single phase heat transfer seem to deviate significantly from the conventional laws in ducts [Qu et al. (2000b), Celata et al. (2002), for example)].

The objective of the present study was to measure the friction factor and the heat transfer coefficient in mini/microchannels and to infer optimal conditions of use from the measurements.

\section{EXPERIMENTAL FACILITY AND PROCEDURE}

\section{Experimental set-up}

Flows of demineralized water in channels of large-span rectangular cross-section and adjustable height were investigated. Details on the facility may be found in Gao et al. (2002a). In the experimental set-up (Fig.1), the active channel walls are two plane brass blocks, which are separated by a foil (thickness e) with a hollowed out central part of width $b(=25 \mathrm{~mm})$. The thickness of this foil fixes the channel height $\mathrm{e}$, which can be varied in the range $0.1-1$ $\mathrm{mm}$ by steps of $0.1 \mathrm{~mm}$. The other dimensions of the channel are $b$ and the length $L(=82 \mathrm{~mm})$. The main advantage of this arrangement is that the channel walls are represented by the same surfaces and that only the channel height $\mathrm{e}$ is varied during all the experiments. The two blocks are rounded off in the upstream part so as to form a convergent channel entrance. They were hand-polished (measured roughness $<0.1$ micron). Two sumps are machined in the working section at the channel inlet/outlet. Heating was provided by four electric cartridges (maximum total power of $4 \times 250 \mathrm{~W}$; typical value of power used in the experiments: $500 \mathrm{~W}$ ), which were inserted inside the two blocks and surrounded by an insulating material.

Typical flow conditions are presented in Table I. The origin of abscissa $\mathrm{x}$ along the channel is the beginning of the straight section.

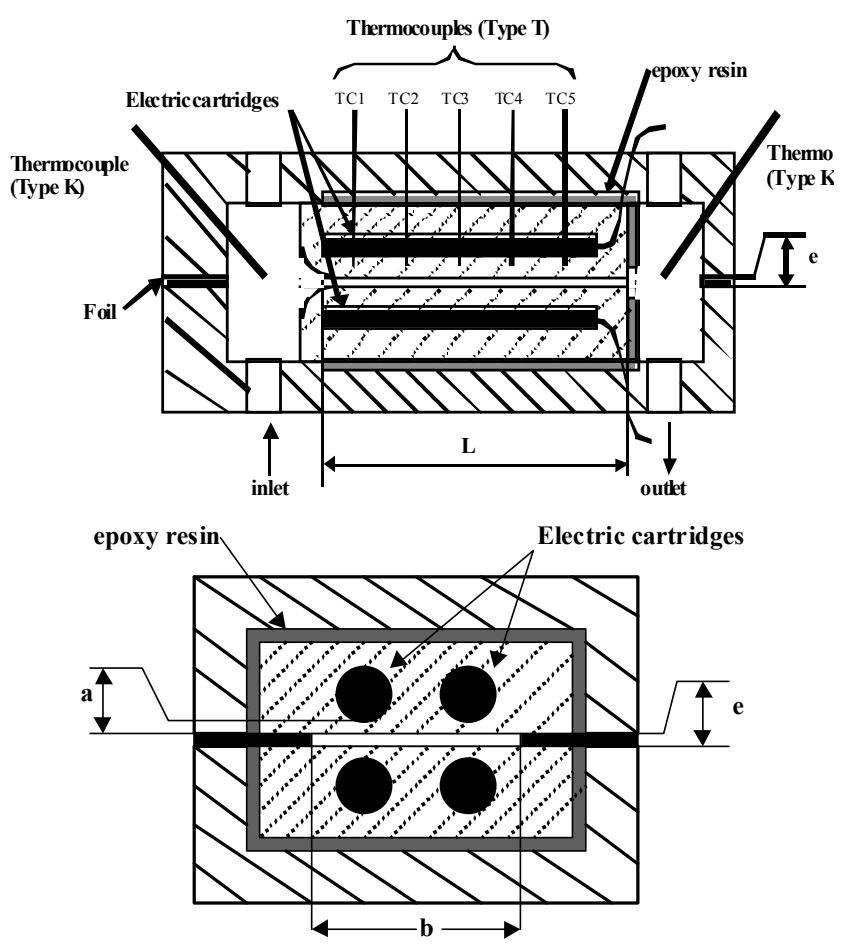

Figure 1. Sketch of the test section 
Table I: Typical flow conditions

\begin{tabular}{|c|c|c|c|c|c|}
\hline $\mathrm{e}$ & $\begin{array}{c}\mathrm{b} \\
\mathrm{mm}\end{array}$ & $\begin{array}{c}\mathrm{L} \\
\mathrm{mm}\end{array}$ & $\begin{array}{c}\mathrm{U} \\
\mathrm{m} / \mathrm{s}\end{array}$ & $\begin{array}{c}\mathrm{Q}_{\mathrm{v}} \\
1 / \mathrm{mn}\end{array}$ & $\mathrm{Re}$ \\
\hline $\begin{array}{c}100 \\
\mu \mathrm{m}\end{array}$ & 25 & 82 & $0.1-10$ & $0.015-1.5$ & $20-2400$ \\
\hline $\begin{array}{c}200 \\
\mu \mathrm{m}\end{array}$ & 25 & 82 & $0.16-15$ & $0.05-4.5$ & $57-6000$ \\
\hline $1 \mathrm{~mm}$ & 25 & 82 & $0.02-4$ & $0.03-6$ & $40-7400$ \\
\hline
\end{tabular}

\section{Instrumentation}

Flowrates were measured with two high-precision turbine flowmeters. The pressure drop $\Delta \mathrm{p}$ was determined by piezo resistive strain gauge transmitters (full scale: $10^{6} \mathrm{~N} \cdot \mathrm{m}^{-2}$ ) at channel inlet/outlet, or by a differential gauge (full scale: $10^{4} \mathrm{~N} . \mathrm{m}^{-2}$ ). Thermocouples of type $\mathrm{K}$ were placed in the two sumps to determine the fluid inlet/outlet temperatures, denoted respectively $T_{\text {in }}$ and $T_{\text {out }}$ Wall temperatures were measured by five thermocouples (denoted $\mathrm{TC}_{1}$ to $\mathrm{TC}_{5}$ ) of type $\mathrm{T}$ (diameter $=0.5 \mathrm{~mm}$ ) placed in $1.5 \mathrm{~cm}$ increments along the channel (position of the first thermocouple $\mathrm{x}=0.6 \mathrm{~cm}$ ). The corresponding sections are denoted "1" to "5". The thermocouples were located in the brass blocks $1 \mathrm{~mm}$ away from the metal-fluid interface.

\section{Data processing}

The data were interpreted by using the Reynolds number $\mathrm{Re}$ and the Nusselt number $\mathrm{Nu}$, which were defined based on the hydraulic diameter $D_{h}$. Re was based on the bulk velocity in the channel. The water properties, such as density, dynamic viscosity, Prandtl number, were determined at the average of the inlet/outlet temperatures $\mathrm{T}_{\mathrm{av}}\left(=1 / 2\left(\mathrm{~T}_{\text {in }}+\mathrm{T}_{\text {out }}\right)\right)$. The thermal conductivity used in $\mathrm{Nu}$ was determined at the local film temperature $T_{\text {film }}$ (average of wall and fluid bulk temperatures; $T_{\text {film }}=1 / 2\left(T_{w}+T_{f}\right)$ ). The friction factor $f$ was determined from the inlet/outlet pressure measurements. The inlet pressure was corrected by the inertia term accounting for flow acceleration in the converging channel entrance.

$$
\begin{aligned}
& \Delta \mathrm{p}=\mathrm{p}_{\text {in }}-\mathrm{p}_{\text {out }}-(1 / 2) \rho \mathrm{V}^{2} \\
& f=\frac{\tau}{(1 / 2) \rho \mathrm{V}^{2}}=\frac{\Delta \mathrm{p}}{2 \rho \mathrm{V}^{2}} \frac{\mathrm{D}_{\mathrm{h}}}{\mathrm{L}}
\end{aligned}
$$

The local wall heat-flux q" was deduced from the electric power $\mathrm{P}$ assumed uniformly distributed along the resistances. The local fluid bulk temperature was deduced from a heat balance between the heat rate exchanged with the walls and the rate of enthalpy convected by the stream. Close agreement was found for the rate of enthalpy convected by the stream across the channel and the electric power dissipated in the blocks, except for very small flowrates. In this last case, incorrect measurements of $\mathrm{T}_{\text {out }}$ are suspected. A one-dimensional model was developed to account for conduction in the metallic slab, which is located between the resistances and the channel. From these computations it was found that the measurements in sections "2" and "3" are not affected by conductive effects and may be used to determine the heat transfer coefficient in the channel (for more details, see Gao et al, 2002a). It was also verified that the local fluid bulk temperature $T_{f}$ may be assumed to vary linearly along the channel over the length $l_{h}$. The heat exchange surface was assumed to correspond to the active length of the resistances $\left(l_{\mathrm{h}}=62 \mathrm{~mm}\right)$. The local Nusselt number was then computed from the measurements by using the following relations

$$
\begin{aligned}
& \mathrm{q}^{\prime \prime}=\frac{\mathrm{P}}{2 \mathrm{bl}_{\mathrm{h}}} \\
& \mathrm{T}_{\mathrm{f}}=\mathrm{T}_{\text {in }}+\left(\mathrm{T}_{\text {out }}-\mathrm{T}_{\text {in }}\right) \frac{\mathrm{x}}{\mathrm{l}_{\mathrm{h}}} \\
& \mathrm{h}=\frac{\mathrm{q}^{\prime \prime}}{\mathrm{T}_{\mathrm{w}}-\mathrm{T}_{\mathrm{f}}} \\
& \mathrm{Nu}_{\mathrm{x}}=\frac{\mathrm{hD}_{\mathrm{h}}}{\mathrm{k}}
\end{aligned}
$$

When $\mathrm{Q}$ was smaller than the electric power $\mathrm{P}$, then $\mathrm{Q}$ was used instead of $P$ in Eq. 2. Uncertainties were analyzed and estimated. The results are given in Table 2.

Table 2: Uncertainty Analysis for $100<\operatorname{Re}<8000$

\begin{tabular}{|c|c|c|c|c|}
\hline \multicolumn{2}{|c|}{$\mathrm{e}(\mathrm{mm})$} & 1 & 0.5 & 0.1 \\
\hline \multirow{2}{*}{$\mathrm{dRe} / \mathrm{Re}$} & Mini & $0.4 \%$ & $0.4 \%$ & $0.4 \%$ \\
\cline { 2 - 5 } & Maxi & $0.8 \%$ & $0.7 \%$ & $0.7 \%$ \\
\hline \multirow{2}{*}{$\mathrm{dNu} / \mathrm{Nu}$} & Mini & $0.6 \%$ & $0.7 \%$ & $0.4 \%$ \\
\cline { 2 - 5 } & Maxi & $7.8 \%$ & $4.9 \%$ & $1.2 \%$ \\
\hline
\end{tabular}




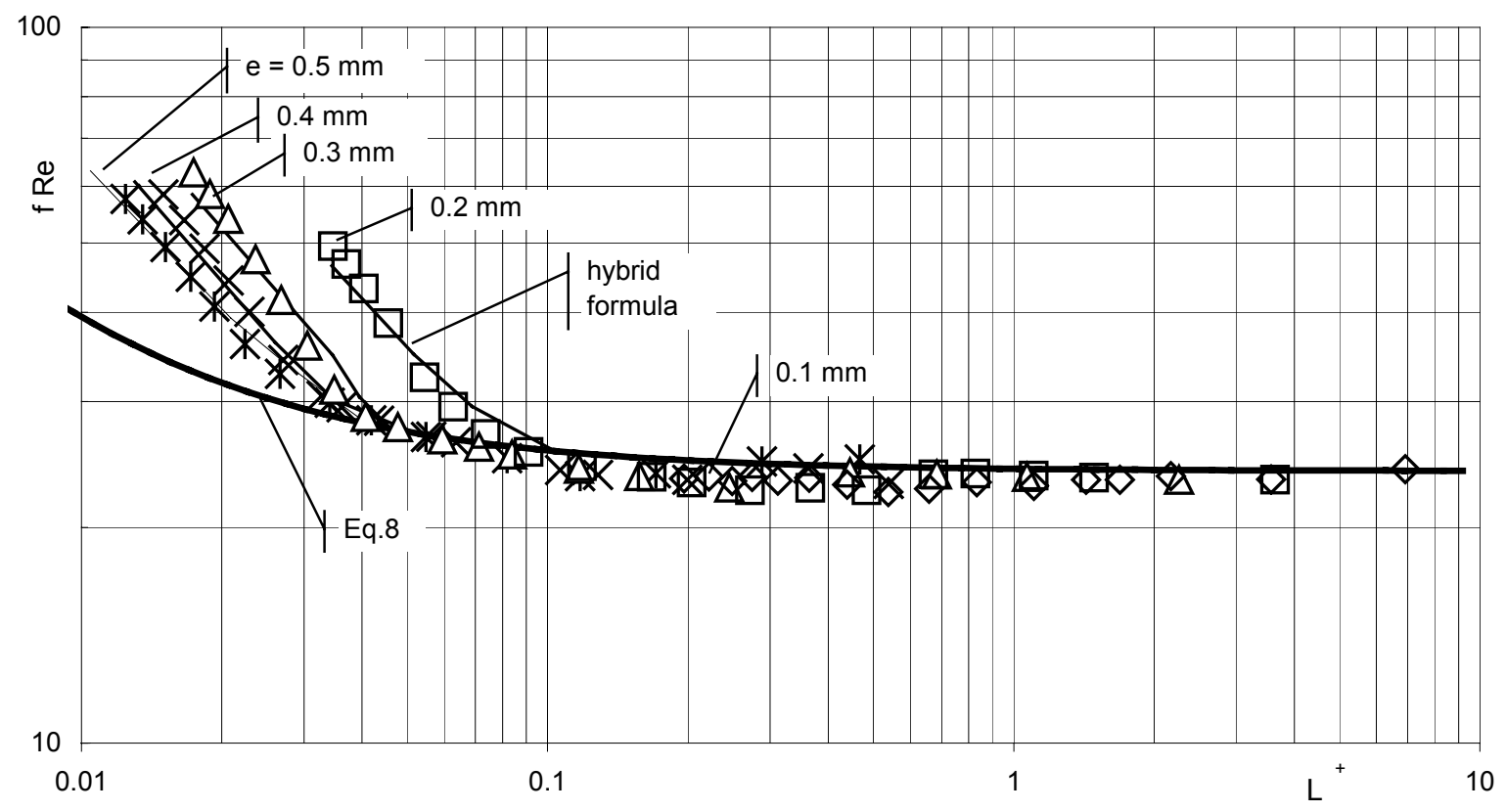

Figure 2. The effect of channel size on the non-dimensional pressure drop

\section{RESULTS}

\section{Friction factor}

For low values of the Reynolds number the flow is laminar, but entrance effects are present and affect the total pressure drop across the channel. The wall boundary layers merge at a distance $\mathrm{x}^{+} \approx 0.04$ (White, 1991). Because the length of the tested channels is fixed, the entrance length depends on the channel height and on the flow velocity. It is therefore helpful to plot the pressure drop as a function of the dimensionless channel length $\mathrm{L}^{+}$. The Poiseuille number

$$
\mathrm{Po}=f \mathrm{Re}
$$

deduced from the measurements is drawn in Fig. 2 for the lowest values of e. The graph also displays the following formula proposed by Shah (1978):

$$
\text { Po }=\frac{3.44}{\sqrt{\mathrm{L}^{+}}}+\frac{24+0.674 / 4 \mathrm{~L}^{+}-3.44 / \sqrt{\mathrm{L}^{+}}}{1+2.9 \times 10^{-5} / \mathrm{L}^{+^{2}}}
$$

Figure 2 shows that the friction law for the developed laminar flow regime ( $f \operatorname{Re}=24)$ is confirmed very well by the present experiment, regardless the channel height (Gao et al., 2002a, b). Eq. 8 slightly overestimates the pressure drop in the range $0.1<\mathrm{L}^{+}<1$. A clear departure from Eq. 8 is observed when $\mathrm{L}^{+}$is lower than a critical value $\mathrm{L}_{\mathrm{c}}^{+}$, which depends on the channel height. $\mathrm{L}_{\mathrm{c}}^{+}$obviously corresponds to a critical value of the Reynolds number $\mathrm{Re}_{\mathrm{c}}$. It was found that $\mathrm{Re}_{\mathrm{c}}$ does not depend significantly from $\mathrm{e}$ and is approximately equal to 3500 , close to the accepted value of 4000 for transition in plane wall channels. This result was also confirmed by visualizations obtained by dye-injection at the channel inlet. Solid lines in Fig. 2 correspond to an hybrid formula using Eq. 8 in the first half of the channel and the Blasius equation

$$
f=0.079 \mathrm{Re}^{-1 / 4}
$$

in the second part of the channel. The good agreement with the experimental data also confirms the existence of the turbulent regime for $\operatorname{Re}>\operatorname{Re}_{\mathrm{c}}$.

\section{Heat transfer coefficient}

For a given flowrate, four values of the local Nusselt number $\mathrm{Nu}_{\mathrm{x}}$ were obtained from the thermocouples TC1 to TC4 by using Equations (3)-(6). As for pressure losses, the local Nusselt number $\mathrm{Nu}_{\mathrm{x}}$ was plotted as a function of $\mathrm{x}^{*}$ $\left(=\mathrm{x} /\left(\mathrm{D}_{\mathrm{h}} \operatorname{Re} \mathrm{Pr}\right)\right)$ in order to identify entrance effects and transition to turbulence in the heat transfer results. Figure 3 shows the results for $\mathrm{e}=0.5 \mathrm{~mm}$ and $\mathrm{e}=0.1 \mathrm{~mm}$. The data of Shah and London (1978) for simultaneous developing flow and heat transfer were interpolated for $\operatorname{Pr}=4$ and displayed on the same figure. 


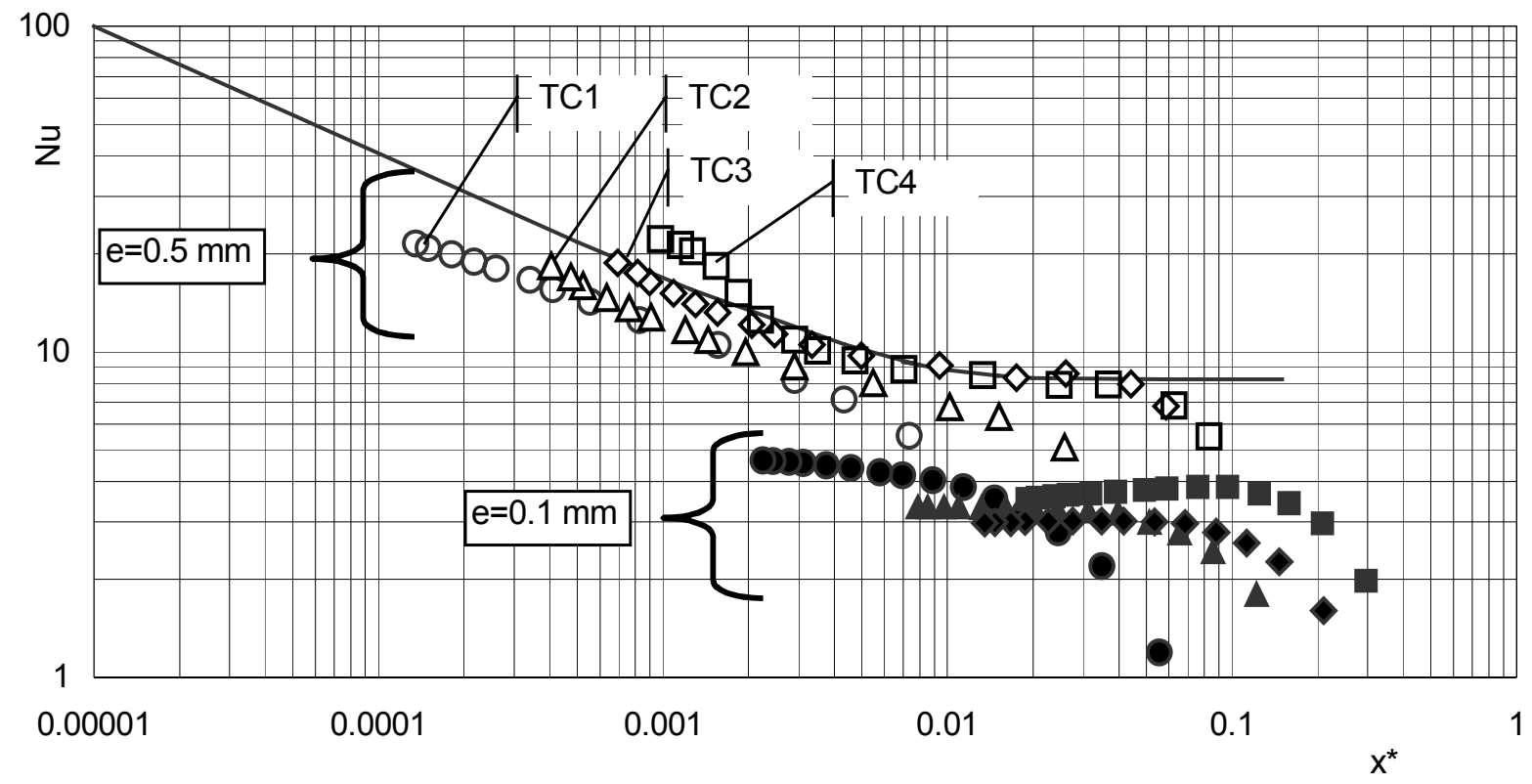

Figure 3. Local Nusselt number

The general trend observed for all the channels tested is in good agreement with the data of Shah and London (1978) for $\mathrm{e} \geq 0.5 \mathrm{~mm}$. There is a significant decrease in $\mathrm{Nu}_{\mathrm{x}}$ when the channel height is decreased below $0.5 \mathrm{~mm}$. A satisfying overlap of the results deduced from the four thermocouples was observed, which confirms that $\mathrm{x}^{*}$ is the relevant parameter for the heat transfer results. However, for each channel height, two systematic deviations from the general trend were observed. A deviation towards low values of $\mathrm{Nu}_{\mathrm{x}}$ and, more generally, an important scatter of the results occur when $x^{*}$ is increased for a given thermocouple, i.e. when the flowrate is decreased. In fact, the observed rapid decrease of $\mathrm{Nu}_{\mathrm{x}}$ is not linked to $\mathrm{x}^{*}$ as can be seen in Fig. 3, but to the small flowrates used in these conditions since it occurs for the same flowrate at the four measurement sections. This reduction of $\mathrm{Nu}_{\mathrm{x}}$ corresponds to the low values of the total enthalpy rise Q measured for the smallest flowrates, as was mentioned before. It is likely that $Q$ is incorrectly determined in these conditions and that the corresponding results for $\mathrm{Nu}_{\mathrm{x}}$ are not reliable. Consequently, they were discarded in the optimization analysis. On the other hand, the values of $\mathrm{Nu}_{\mathrm{x}}$ given by TC4 are significantly above the other results for small values of $x^{*}(<0.002$ for $\mathrm{e}=0.5 \mathrm{~mm}$ in Fig.3) for all the channels. This range of $x^{*}$ corresponds to TC4 at the highest flowrates and highest Re used in the experiments. The Reynolds number found for the change of slope in the $\mathrm{Nu}_{\mathrm{x}}$-curve is close to the value deduced from pressure losses measurements. Consequently this change of regime for heat transfer may be probably attributed to transition to turbulence in the microchannel.

The significant decrease observed in the Nusselt number with the size of the channel is in agreement with previously published results [Qu et al. (2000b), Celata et al. (2002)]. Figure 3 shows that it can reach a factor of about $30 \%$ for e $=0.1 \mathrm{~mm}(\mathrm{Nu} \approx 3$ instead of 8.23 for the fully-developed laminar regime).

\section{Optimal spacing of the plates in a micro-heat exchanger}

The optimal spacing for maximum heat transfer from a package of parallel plates was investigated both theoretically and numerically by Bejan and Sciubba (1992) (see also Bejan (2000)). In this study, the authors considered an arrangement of parallel plates cooled by forced convection and found a maximum heat transfer rate for fixed pressure drop and fixed inlet and wall temperatures. They showed that the relevant parameters are the dimensionless heat transfer rate density 


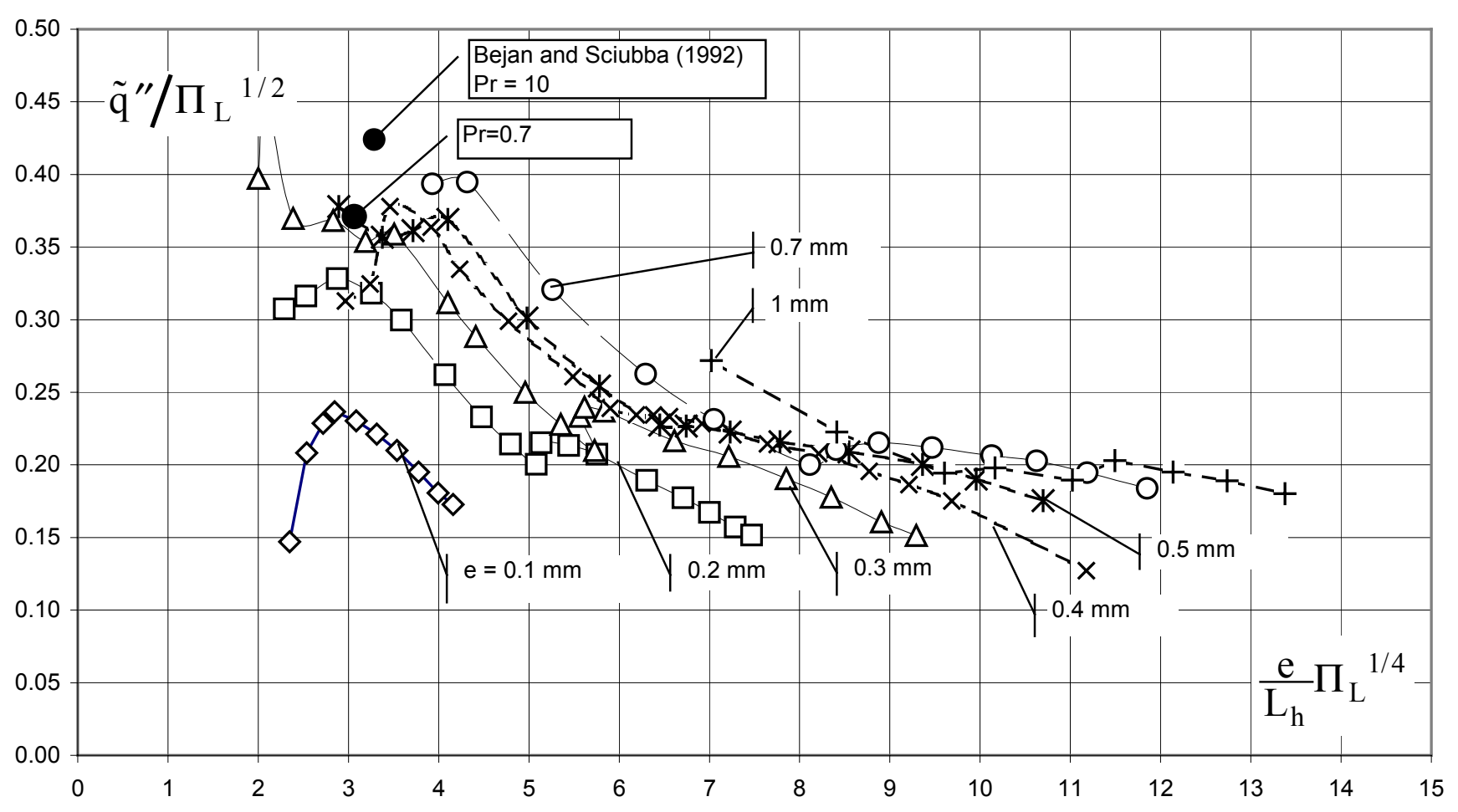

Figure 4. Optimal spacing for maximum heat transfer

$$
\widetilde{\mathrm{q}}^{\prime \prime}=\frac{2 \mathrm{q}^{\prime \prime}}{\mathrm{e} \quad \mathrm{k}\left(\mathrm{T}_{\mathrm{max}}-\mathrm{T}_{\min }\right)}
$$

and the pressure drop number

$$
\Pi_{\mathrm{L}}=\frac{\Delta \mathrm{p}_{\mathrm{L}_{\mathrm{h}}} \mathrm{L}_{\mathrm{h}}^{2}}{\mu \alpha}
$$

where $\Delta \mathrm{p}_{\mathrm{L}_{\mathrm{h}}}$ is the pressure drop over a channel of length $\mathrm{L}_{\mathrm{h}}$. $\mathrm{T}_{\max }$ is the wall temperature for $\mathrm{x}=\mathrm{L}_{\mathrm{h}}$ and $\mathrm{T}_{\min }$ is the fluid inlet temperature. The analysis suggests that the optimal spacing for maximum heat transfer is given by

$$
\mathrm{e} / \mathrm{L}_{\mathrm{h}}=\mathrm{a}_{1} \Pi_{\mathrm{L}}^{-1 / 4}
$$

and that the maximum power density satisfies

$$
\tilde{\mathrm{q}}^{\prime \prime}=\mathrm{a}_{2} \Pi_{\mathrm{L}}{ }^{1 / 2}
$$

The constants $a_{1}$ and $a_{2}$ are slightly dependent on $\operatorname{Pr}$ and on the thermal boundary conditions. Bejan and Sciubba (1992) found: $a_{1}=3.077, a_{2}=0.522$ for $\operatorname{Pr}=6$ and isothermal surfaces, $a_{1}=3.287, a_{2}=0.424$ for $\operatorname{Pr}=10$ and uniform heat flux surfaces.
The experimental data were analyzed by using this scale analysis. The actual conditions of heating were close to the case of a constant-flux channel. However, the maximum temperature did not occur at the channel exit, owing to the reduced heating resistance length, as mentioned before. The section " 3 " of the thermocouple TC3 $(\mathrm{x}=3.6 \mathrm{~cm})$ was chosen to analyze the data because it is not affected by wall conduction effects regardless the flow conditions and may be assumed to be in a region of constant heat-flux for all the channels (Gao et al, 2002). The pressure drop between inlet and section "3" was computed by the following relation:

$$
\Delta \mathrm{p}_{\text {inlet - "3" }}=\Delta \mathrm{p}-\Delta \mathrm{p}_{\text {"3" }} \text { - outlet }
$$

where $\Delta \mathrm{p}$ is the total pressure drop across the channel. $\Delta \mathrm{p}$ "3" - outlet was estimated by the classical laws of friction for fully developed flow in the laminar or the turbulent regime, depending on the value of Re. When the resulting $\Delta p_{\text {inlet - S3 }}$ was less than $100 \mathrm{Nm}^{-2}$, the data were discarded because the resulting pressure difference corresponds to the accuracy of the differential pressure transmitter.

Following the results of the theoretical analysis (Eq. (12-13)), the present data are plotted by using $\widetilde{\mathrm{q}}^{\prime \prime} / \Pi_{\mathrm{L}}{ }^{1 / 2}$ as a function of $\frac{\mathrm{e}}{\mathrm{L}_{\mathrm{h}}} \Pi_{\mathrm{L}}{ }^{1 / 4}$ in Fig.4. Despite the lack of 
measurements for very low values of $\frac{\mathrm{e}}{\mathrm{L}_{\mathrm{h}}} \Pi_{\mathrm{L}}{ }^{1 / 4}$, the present results clearly show an optimal spacing for $\frac{\mathrm{e}}{\mathrm{L}_{\mathrm{h}}} \Pi_{\mathrm{L}}{ }^{1 / 4} \approx 3$ for the narrowest microchannels $(\mathrm{e}=0.1-0.4 \mathrm{~mm})$, which were investigated. The maximum values of $\widetilde{q}^{\prime \prime} / \Pi_{L}^{1 / 2}$ are slightly less than predicted by the theory, but the agreement with Bejan and Sciubba's analysis is good. The curve corresponding to $\mathrm{e}=0.1 \mathrm{~mm}$ is shifted toward lower values of $\widetilde{q}^{\prime \prime} / \Pi_{L}^{1 / 2}$. This is due to the strong reduction in the Nusselt number, which was observed for these conditions (Fig. 3). Very few points were obtained on the left branch of the curves of Fig. 4, especially for e $>0.5 \mathrm{~mm}$, because they correspond to a very low pressure drop across the channel and consequently to the low range of the differential pressure transmitter.

The theoretical analysis shows that the position of the $\tilde{\mathrm{q}}^{\prime \prime}$ maximum corresponds to $\mathrm{x}^{*} \approx 0.04$. Bejan and Sciubba remarked that the optimal spacing is therefore such that the channel length is equal to the thermal entrance length. The present experiments give close agreement with this theoretical prediction for $\mathrm{e}=0.1 \mathrm{~mm}\left(\mathrm{x}^{*}=0.046\right)$ and for $\mathrm{e}$ $=0.2 \mathrm{~mm}\left(\mathrm{x}^{*}=0.041\right)$. The agreement deteriorates for $\mathrm{e}=$ $0.4 \mathrm{~mm}\left(\mathrm{x}^{*}=0.018\right)$, but the position of the maximum is not well defined in this case (Fig. 4).

\section{CONCLUSION}

Two-dimensional microchannels were investigated in the present study. The design of the test section enabled variations of the channel height by steps of $0.1 \mathrm{~mm}$, from 1 $\mathrm{mm}$, which corresponds to minichannels to the smallest height of $0.1 \mathrm{~mm}$, where size effects were suspected to affect the flow dynamics and heat transfer. Flow and heat transfer measurements were first interpreted by using a dimensionless distance to the channel inlet (respectively, $\mathrm{L}^{+}$ or $\left.\mathrm{x}^{*}=\mathrm{x} /\left(\mathrm{D}_{\mathrm{h}} \operatorname{Re} \operatorname{Pr}\right)\right)$. This presentation clearly identifies entrance effects and transition to turbulence. The results show that the classical laws of friction in two-dimensional ducts are well verified both in the laminar and the turbulent regimes. In fact, no scale effects were found in the present experiments for the flow hydrodynamics. Heat transfer laws are also well verified for the minichannels of the present study in the laminar regime (e $\geq 0.5 \mathrm{~mm}$ ). However, for $\mathrm{e}<$ $0.5 \mathrm{~mm}$, the plots of $\mathrm{Nu}_{\mathrm{x}}\left(\mathrm{x}^{*}\right)$ show a departure from the classical heat transfer law, which grows when the channel height is decreased. The reduction of $\mathrm{Nu}$ is very strong for the narrowest microchannels. For e $=0.1 \mathrm{~mm}, \mathrm{Nu}$ is about $60 \%$ smaller than the conventional value for large-scale channels.

One objective of the study was to investigate optimization of two-dimensional channels and to test the theoretical and numerical results of Bejan and Sciubba (1992). For this purpose, the experimental data were interpreted by using the dimensionless parameters first introduced by these authors. This corresponds to conditions of fixed pressure drop and maximum wall temperature in the channels. Although the range of the dimensionless spacing $\frac{\mathrm{e}}{\mathrm{L}_{\mathrm{h}}} \Pi_{\mathrm{L}}{ }^{1 / 4}$ is rather limited in the present study, especially for low values of this parameter, an optimal spacing is clearly identified when the dimensionless heat flux $\widetilde{\mathrm{q}}^{\prime \prime} / \Pi_{\mathrm{L}}{ }^{1 / 2}$ and spacing $\frac{\mathrm{e}}{\mathrm{L}_{\mathrm{h}}} \Pi_{\mathrm{L}}{ }^{1 / 4}$ are used to interpret the data. The present experiments support well the predictions of Bejan and Sciubba (1992), except the smaller values of maximum heat transfer rate density, which may be attributed to microscale effects. This is the first time that the optimal spacing between parallel plates was determined experimentally

Further experiments will be conducted with other surface finish in order to identify the phenomena governing this flow. In particular, it is planned to carry out investigations of microchannel flows with rough walls. Further insight in the flow phenomena should be provided by visualizations, which will be soon performed in a test section with transparent walls. Measurements with microsensors are also planned in the near future.

\section{ACKNOWLEDGEMENTS}

This research was supported by the CNRS and Region Rhône-Alpes. The authors would like to gratefully acknowledge Institut National Polytechnique de Grenoble for supporting the stay of A. Bejan in Grenoble. They also wish to thank P.Gao for performing the experiments.

\section{REFERENCES}

Bejan A., Shape and Structure, from Engineering to Nature, Cambridge University Press, Cambridge, UK (2000), chapter 3 .

Bejan A., Sciubba E., The optimal spacing of parallel plates cooled by forced convection, Int. J. Heat Mass Transfer, 35 (1992), 3259-3264.

Celata G.P., Cumo M., Guglielmi M., Zummo G., Experimental investigation of hydraulic and single-phase heat transfer in $0.130-\mathrm{mm}$ capillary tube, Microscale Thermophysical Engineering, 6 (2002), 85-97.

Flockhart, S.M., Dhariwal, R.S., Experimental and numerical investigation into the flow characteristics of channels etched in $<100>$ silicon, J. Fluids Engineering, 120 (1998), 291-295.

Gao P., Le Person S., Favre-Marinet M., Scale effects on hydrodynamics and heat transfer in two-dimensional mini and microchannels, Int. J. Thermal Sciences, 41, (2002a) 1017-1027. 
Gao P., Le Person S., Favre-Marinet M., Hydrodynamics and heat transfer in two-dimensional microchannels, $12^{\text {th }}$ Int. Heat Transfer Conf (2002b), Grenoble, France.

Pfund D., Rector D., Shekarriz A., Popescu A., Welty J., Pressure drop measurements in a microchannel, AIChE J., 46 (2002), 8, 1496-1507.

Qu W., Mala G.M., Li D., Pressure-driven water flows in trapezoidal silicon microchannels, Int. J. Heat Mass Transfer, 43 (2000a), 353-364.

Qu W., Mala G.M., Li D., Heat transfer for water flows in trapezoidal silicon microchannels, Int. J. Heat Mass Transfer, 43 (2000b), 3925-3936.
Shah R.K., A correlation for laminar hydrodynamic entry length solutions for circular and noncircular ducts, J. Fluids Engng., 100 (1978), 177-179.

Shah R.K., London A.L., Laminar flow forced convection in ducts, Advanced heat transfer (1978), Academic Press New York.

Tuckermann D.B., Pease R.F., Optimized convective cooling using micromachined structure, J. Electrochem. Soc., 129, 3 (1982) p C98.

White F.M., Viscous Fluid Flow, 2nd Edition, McGrawHill,Inc, New-York, (1991). 